\title{
Dynamic Analysis of Shaft System of Micro Bubble Generating Pump
}

\author{
Hilman Syaeful Alam, Bahrudin, and Anto Tri Sugiarto
}

\begin{abstract}
Gas-liquid mixing pump is one type of microbubble generator which is very efficient for mixing gas and liquid directly and dissolve them. However, one of the problems in designing the rotating machinery is the vibration, because the vibration is usually a direct cause of the component damage. In this paper, the dynamic characteristic of shaft system on a micro bubble generating pump was evaluated based on finite element analysis using ANSYS to investigate the stability and the critical speed of the system. Based on the results of evaluation, finite element analysis can predict the vibration modes on the entire segment of the shaft system in accordance with the natural frequencies of the respective modes. However, it did not find any critical speeds below the design rotational velocity of the shaft system. It can be concluded that the shaft system of the gas-liquid mixing pump was still outside the resonance region and the structural design of the shaft system could be operated safely..
\end{abstract}

Index Terms-Finite element, Campbell diagram, natural frequency, micro bubble, gas-liquid mixing pump.

\section{INTRODUCTION}

Microbubble technologies have been the subject of intensive research over the past decade, due to their wide applications in various industries and processes, such as: flotation and separation in mineral processing industry [1], polishing slurry used in precise mechanical polishing [2], processing of leaching water [3], and wastewater treatment [4], [5]. Microbubbles (MBs) are tiny bubbles with a respective diameter of 10-50 $\mu \mathrm{m}$ [5]. Microbubbles can be generated by number of ways and can be classified into four methods, i.e. with accompanying liquid flow, without accompanying liquid flow, by polymer, and low power generation techniques [6]. The first method is the most widely used methods for generating microbubbles in large numbers. Gas-liquid mixing pump is one type of microbubble generator that is designed based on hydrodynamic principles, which is very efficient at mixing gas and liquid directly and dissolve them.

One of the problems in designing the gas-liquid mixing pump as a rotating machinery is the vibration because the vibration is usually a direct cause of the component damage.

Manuscript received April 1, 2016; revised June 27, 2016. This work was financed by Kegiatan Unggulan LIPI, Indonesian Institute of Sciences under Grant 1139/F/2015-03-06. The computational facilities were extended by the Research Center of Electrical Power and Mechatronics, Indonesian Institute of Sciences, which is thankfully acknowledged.

The authors are with the Technical Implementation Unit for Instrumentation Development, Indonesian Institute of Sciences, J1. Sangkuriang Komplek LIPI, Gd. 30, Bandung, Indonesia, 40135 (e-mail hilm003@lipi.go.id, bahr003@lipi.go.id, author@nrim.go.jp).
Dynamic analysis is essential for quantifying safe upper limits of allowable vibration levels by analyzing the critical speed of the rotor system. It can provide information about the resonance region of the system which can be used as a reference to monitor the possibility of harmful, due to damage of the components. Therefore, it is very useful for designers in understanding the relationship between the selection of design schemes including the shaft size, bearing properties, housing stiffness, and machine stability [7], [8].

According to Bai et al. [9], there are two methods which are used to solve a dynamic problem of the rotor system, i.e. transfer matrix method and finite element method (FEM). However, the second method is more popular than the first method. The key idea of the FEM is to transform the infinite DOF (Degrees Of Freedom) problem into a finite number of DOF, and then solve it. FEM has several advantages such as reduction of time when solving complex equation system. In addition, it can be applied to the software and can be widely applied to solving problems in the engineering field for high accuracy and flexibility [10]. Some previous research have been used FEM to evaluate the dynamic characteristics of the rotating system for some applications, such as rotor-shaft system of journal bearings [11], rotor of IPM motor [12], generator rotor of gas turbine [13], gear pump [14], air bearing spindle [15], and screw pump [16]. In this study, the dynamic characteristic of the gas-liquid mixing pump rotor is evaluated using finite element method, in order to determine the existence of a critical speed and safe upper limits of allowable vibration levels. Therefore, it can be used as a reference for the design or improvement.

\section{MATERIALS AND METHODS}

The main part of gas-liquid mixing pump consists of an electrical motor, coupling, bearing housing, and casing pump as shown in Fig. 1(a), where the main shaft system can be seen in Fig. 1(b). There are two suctions or inlet fluids of mixing pump, i.e. gas and liquid which is mixed by the impeller component. Gas bubbles will be obtained at the outlet of the impeller in line with the increasing pressure at every level of the blade component. The mixing pump is designed to work on a rotation of $3000 \mathrm{rpm}$ with a power of $1.5 \mathrm{hp}$.

Dynamic characteristic evaluation is to analyze the characteristic of inertia effects which can improve the design and decrease the possibility of failure of the shaft system. According to Canonsburg [17], an important part of the inertia effects is the gyroscopic moment which is introduced by the precession motion of the vibrating rotor as it spins. As spin velocity increases, the gyroscopic moment acting on the rotor becomes critically significant. Not accounting for these 
effects at the design level can lead to bearing and/or support structure damage. Accounting for bearing stiffness and support structure flexibility, and then understanding the resulting damping behavior is an important factor in enhancing the stability of a vibrating rotor. In this study, the dynamic analysis of the shaft system was evaluated numerically based on a finite element analysis. ANSYS, a commercial software based on three-dimensional (3D) finite element analysis was used for analyzing the critical speed of the shaft system.

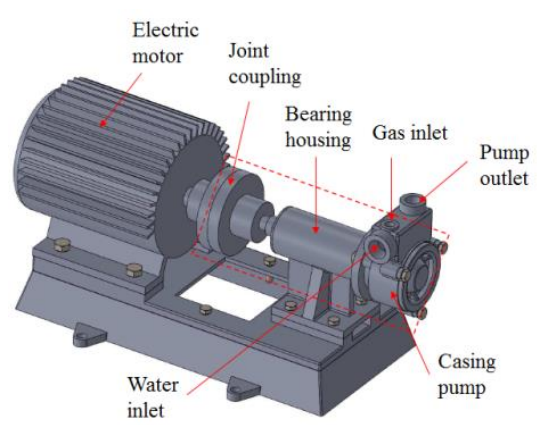

(a)

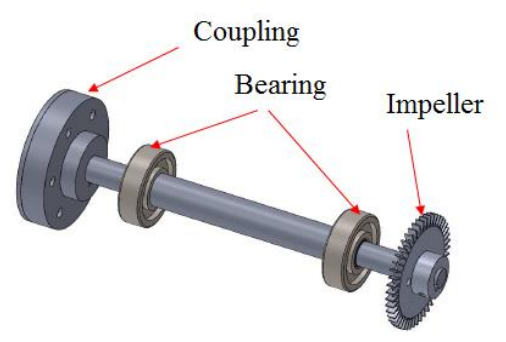

(b)

Fig. 1 (a) Gas-liquid mixing pump, (b) main shaft system. [18]:

The general dynamic equation of the shaft system is [17],

$$
[M]\{\ddot{U}\}+[C]\{\dot{U}\}+[K]\{U\}=\{f\}
$$

where $[M],[C]$, and $[K]$ are the mass, damping and stiffness matrices and $\{f\}$ is the external force vector. In rotor-dynamics analysis, this equation gets additional contributions from the gyroscopic effect $[G]$, and the rotating damping effect $[B]$ leading:

$$
[M]\{\ddot{U}\}+[G]+[C]\{\dot{U}\}+[B]+[K]\{U\}=\{f\}
$$

The gyroscopic matrix, $[G]$, depends on the rotational velocity (or velocities if parts of the structure have different spins) and is the major contributor to rotor-dynamic analysis. This matrix is unique to rotor-dynamic analyzes and is addressed specifically to certain commands and elements. The rotating damping matrix, $[B]$ also depends upon the rotational velocity. It modifies the apparent stiffness of the structure and can produce unstable motion [17].

The first stage in the simulation is building the model in 3D using ANSYS Design Modeler. The second stage is to determine the material of each component of the system, where materials for the three main components, namely: shaft, impeller, and the clutch are respectively made from S45C steel, stainless steel and steel SUS 304 ST 37. The third step is to determine the boundary condition (BC) of the model. The first $\mathrm{BC}$ is to determine the rotational velocity of the shaft system, which determined the maximum rotation of
$3000 \mathrm{rpm}$ or $314.29 \mathrm{rad} / \mathrm{s}$. Omega command was chosen because all the components in a rotating state.

To calculate the gyroscopic effect, the Coriolis command was determined in all rotating parts, then the rotating damping effect was determined by selecting the stiffness coefficient of $1 \times 10^{-6}$. The next stage in the simulation is meshing the models. In meshing, element type needs to be determined to support the gyroscopic effect. We use 3D tetrahedral element, which all rotating parts are determined axisymmetric. The last stage is solving the model, which the modal analysis and Campbell diagram were conducted to review the stability and the critical speed of the model.

\section{RESUlTS AND DISCUSSION}

The results of the model discretization or meshing in ANSYS using 3D tetrahedral element can be seen in Fig. 2. The meshing process produces 19,871 nodal and 10,298 elements. The number of elements in the complex geometry with a small dimension will be greater than the simple geometry with a large dimension. The number of nodal and elements will determine the iteration number and computational time during the calculation process.

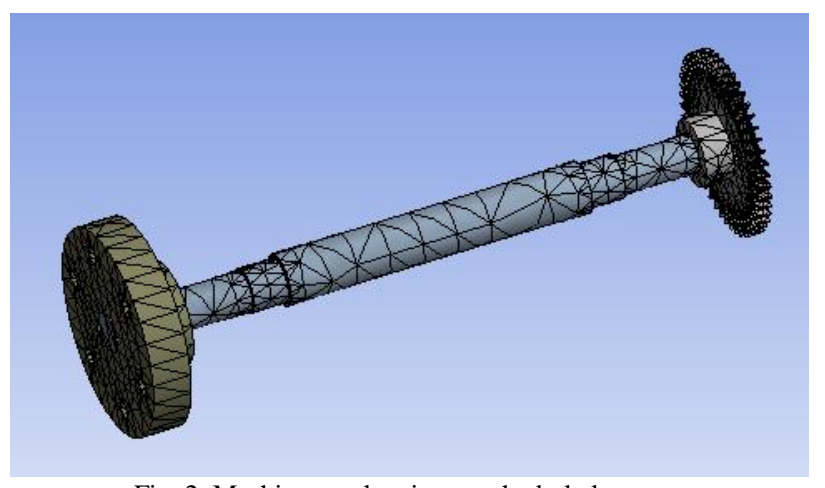

Fig. 2. Meshing result using tetrahedral elements.

The iteration results and calculation process for each natural frequency at the design rotational velocity of 3000 rpm for the first six modes can be represented in Table I. The resonant frequency vibrates when the rotating structure can change points on the spin axis undergo an orbital motion, called whirling. The second, the fifth and the sixth order are in the forward whirl mode (FW) or in the same direction as the rotational velocity and the others are left in the backward whirl (BW).

\begin{tabular}{lll}
\multicolumn{3}{l}{ TABLE I: NATURAL FREQUENCIES OF THE FiRST SiX MODES } \\
\hline Mode & Whirl direction & Natural frequency $(\mathrm{Hz})$ \\
\hline $1^{\text {st }}$ & BW & 716.14 \\
$2^{\text {nd }}$ & FW & 740.62 \\
$3^{\text {rd }}$ & BW & 908.45 \\
$4^{\text {th }}$ & BW & 1467 \\
$5^{\text {th }}$ & FW & 1485.9 \\
$6^{\text {th }}$ & FW & 2222.6 \\
\hline
\end{tabular}

Based on the Campbell diagram in Fig. 3, all modes do not indicate the existence of the critical speed on the system. Therefore, based on the evaluation results, the mixing pump with the maximum speed of $3000 \mathrm{rpm}$ can be operated safely. 
The other simulation result is the modal map for the first six modes that are shown in Fig. 4. The first, the second, and the third modes appear to be a lateral and torsional vibration at the coupling side of the shaft system while the others left shows that the lateral and torsional vibration occurs on the impeller side of the shaft system.

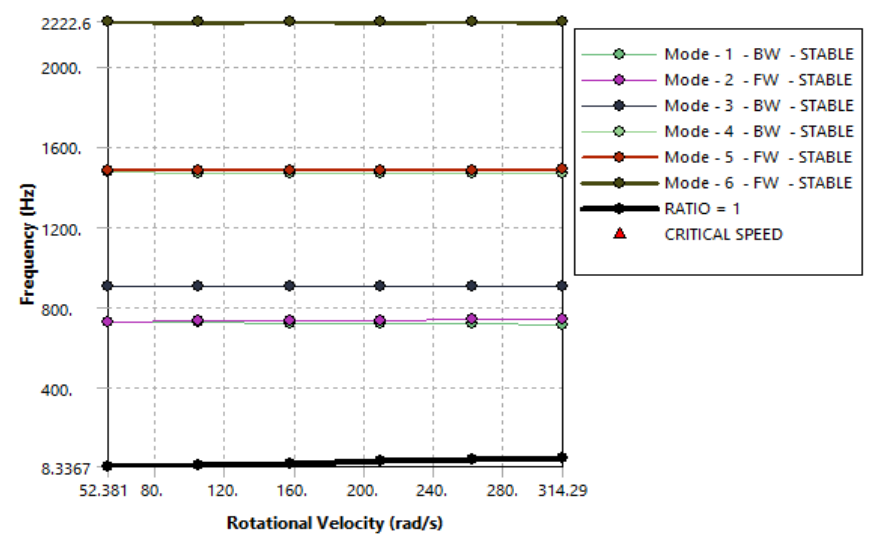

Fig. 3. The Campbell diagram.

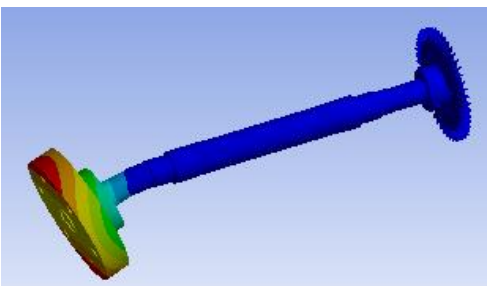

(a)

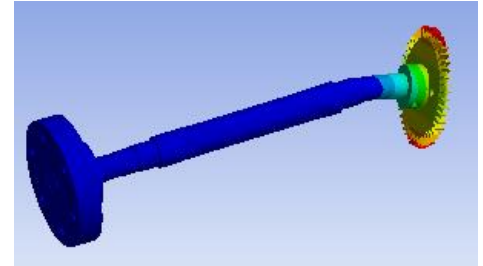

(d)

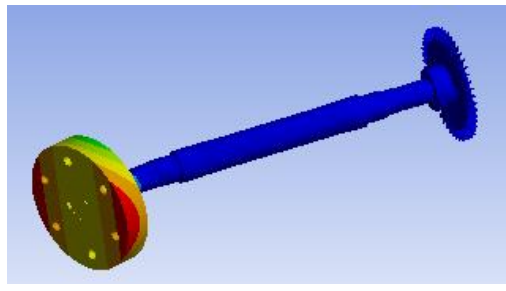

(b)

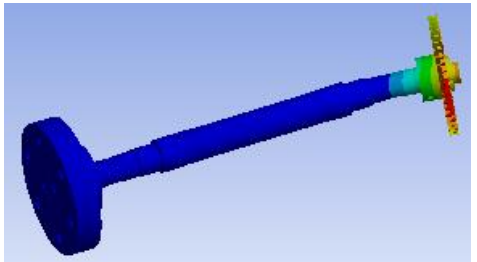

(e)

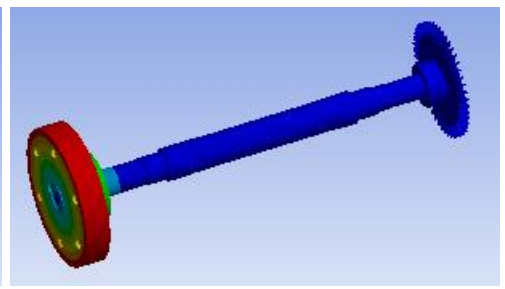

(c)

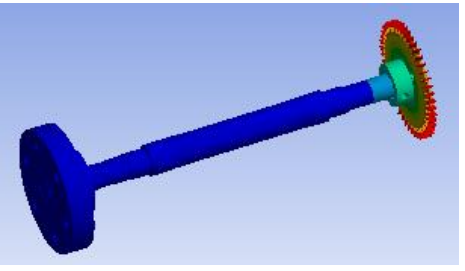

(f)

Fig. 4. The modal maps of (a) 1st, (b) 2nd, (c) 3rd, (d) 4th, (e) 5th, and (d) 6th of order.

\section{CONCLUSION}

The dynamic characteristics using ANSYS was capable of displaying the detailed results for each segment of the shaft system. Based on the results of the modal analysis, the vibration can occur on the coupling side and the impeller side of the shaft system in accordance with the natural frequencies of the respective modes. However, based on the Campbell diagram, it did not find any critical speeds below the design rotational velocity of $3000 \mathrm{rpm}$. It can be concluded that the shaft system of the gas-liquid mixing pump was still outside the resonance region and the structural design of the shaft system could be operated safely.

\section{ACKNOWLEDGMENT}

This work was financed by Kegiatan Unggulan LIPI, Indonesian Institute of Sciences under Grant 1139/F/2015-03-06. The computational facilities were extended by the Research Center of Electrical Power and Mechatronics, Indonesian Institute of Sciences, which is thankfully acknowledged.

\section{REFERENCES}

[1] X. Yan, J. Liu, Y. Cao, and L. Wang, "A single-phase turbulent flow numerical simulation of a cyclonic-static micro bubble flotation column,” Int. J. Min. Sci. Technol., vol. 22, no. 1, pp. 95-100, 2012.
[2] H. Aida, S. W. Kim, K. Ikejiri, T. Doi, T. Yamazaki, K. Seshimo, K. Koyama, H. Takeda, and N. Aota, "Precise mechanical polishing of brittle materials with free diamond abrasives dispersed in micro-nano-bubble water," Precis. Eng., vol. 40, pp. 81-86, 2015.

[3] K. Suzuki, C. Li, and S. Zhang, "Simple processing technology of leaching water using $\mathrm{CO}_{2}$ micro bubbles Supported by the National Science Foundation for Excellent Young Scholars (21422607).," Chinese J. Chem. Eng., vol. 23, no. 11, pp. 1871-1874, 2015.

[4] X. Li, H. Xu, J. Liu, J. Zhang, J. Li, and Z. Gui, "Cyclonic state micro-bubble flotation column in oil-in-water emulsion separation," Sep. Purif. Technol., 2016.

[5] A. Agarwal, W. J. Ng, and Y. Liu, "Principle and applications of microbubble and nanobubble technology for water treatment," Chemosphere, vol. 84, no. 9, pp. 1175-1180, 2011.

[6] R. Parmar and S. K. Majumder, "Microbubble generation and microbubble-aided transport process intensification-A state-of-the-art report," Chem. Eng. Process. Process Intensif., vol. 64, pp. 79-97, 2013.

[7] F. Trebu, P. Frankovský, M. Gu, and P. Hudák, Numerically Computed Dynamics Rotor Using Ansys Software, pp. 498-501, 2011.

[8] I. Djunaedi, H. S. Alam, and A. S. Nugraha, "Rotor-dynamic characteristic evaluation of generator geothermal power plant using finite element method," Appl. Mech. Mater., vol. 664, pp. 170-174, Oct. 2014.

[9] B. Bai, L. Zhang, T. Guo, and C. Liu, "Analysis of dynamic characteristics of the main shaft system in a hydro-turbine based on ANSYS," Procedia Eng., vol. 31, no. 2011, pp. 654-658, 2012.

[10] H. Taplak and M. Parlak, "Evaluation of gas turbine rotor dynamic analysis using the finite element method," Measurement, vol. 45, no. 5 , pp. 1089-1097, 2012.

[11] M. Chouksey, J. K. Dutt, and S. V. Modak, "Modal analysis of rotor-shaft system under the influence of rotor-shaft material damping and fluid film forces," Mech. Mach. Theory, vol. 48, no. 1, pp. 81-93, 2012 . 
[12] H. S. Alam and P. Irasari, "Rotor-dynamic characteristic evaluation of interior permanent magnet motor using finite element method," Mechatronics, Electr. Power, Veh. Technol., vol. 5, no. 1, pp. 1-8, 2014.

[13] A. Sukma Nugraha, I. Djunaedi, and H. S. Alam, "Evaluation of critical speed of the rotor generator system based on ANSYS," in Applied Mechanics and Materials, 2015, vol. 799, pp. 625-628.

[14] E. Mucchi, A. Rivola, and G. Dalpiaz, "Modelling dynamic behaviour and noise generation in gear pumps: Procedure and validation," Appl. Acoust., vol. 77, pp. 99-111, 2014.

[15] R. Dupont, "Robust rotor dynamics for high-speed air bearing spindles," Precis. Eng., vol. 40, pp. 7-13, 2015.

[16] W. Li, H. Lu, Y. Zhang, C. Zhu, X. Lu, and Z. Shuai, "Vibration analysis of three-screw pumps under pressure loads and rotor contact forces," J. Sound Vib., vol. 360, pp. 74-96, 2016.

[17] T. D. Canonsburg, "Rotordynamic Analysis Guide," Knowl. Creat. Diffus. Util., vol. 15317, pp. 724-746, 2009.

[18] G. F. M. Lalanne, Rotordynamics Prediction in Engineering, 2nd Ed. John Wiley and Sons Ltd, United Kingdom, 1998, pp. 1-248.

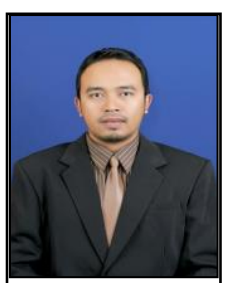

Hilman Syaeful Alam received his bachelor degree in mechanical engineering from Jenderal Achmad Yani University, Indonesia in 2003 and master degree in mechanical engineering from Institut Teknologi Bandung, Indonesia in 2010. He worked as a researcher at Indonesian Institute of Sciences (LIPI) from 2006 until now. His research areas are mechanical engineering, energy conversion, engineering design, intelligent material \& structures, instrumentation \& control, finite element and computational mechanics.

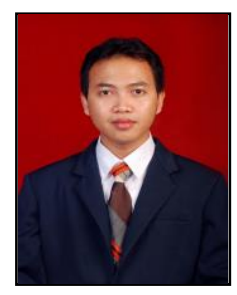

Bahrudin received his bachelor degree in mechanical engineering from Brawijaya University, Indonesia in 2012. He worked as a researcher candidate at Indonesian Institute of Sciences (LIPI) from 2014 until now. His research areas are renewable energy, optimization, fluid mechanic, finite element, and instrumentation \& control.

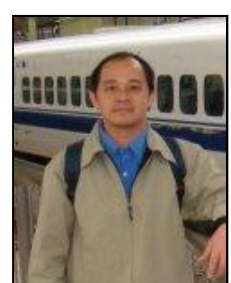

Anto Tri Sugiarto received his bachelor degree in electrical engineering from Nihon University, Japan in 1996, Master degree in electrical engineering from Nihon University, Japan in 1998, and doctoral degree in electrical engineering in Gunma University, Japan in 2002. He worked as a researcher at Indonesian Institute of Sciences (LIPI) from 1990 until now. His research areas are plasma technology, ozone for the environment, and instrumentation \& control. 